\title{
EFFECTIVE PHARMACOGENOMIC-DRIVEN TREATMENT OF MAJOR DEPRESSION: A CASE REPORT
}

\author{
Dragan Primorac ${ }^{1,2,3,4,5,6,7,8, *}$, Alen Juginović ${ }^{1}$, Igor Filipčić ${ }^{4,9,10}$, Ivan Mikula ${ }^{1}$, Ines Lazibat ${ }^{4,11}$, \\ Morana Brkljačićc ${ }^{12}$ \& Damir Erceg ${ }^{1,3,4,12,13, *}$ \\ ${ }^{I}$ St. Catherine Specialty Hospital, Zagreb \& Zabok, Croatia \\ ${ }^{2}$ University of Split School of Medicine, Split, Croatia \\ ${ }^{3}$ University of Osijek School of Medicine, Osijek, Croatia \\ ${ }^{4}$ University of Osijek Faculty of Dental Medicine and Health, Osijek, Croatia \\ ${ }^{5}$ University of Rijeka School of Medicine, Rijeka, Croatia \\ ${ }^{6}$ Eberly College of Science, 517 Thomas St, State College, Penn State University, USA \\ ${ }^{7}$ The Henry C. Lee College of Criminal Justice and Forensic Sciences, University of New Haven, West Haven, USA \\ ${ }^{8}$ Medical School REGIOMED, Coburg, Germany \\ ${ }^{9}$ Psychiatry Hospital „Sveti Ivan“, Zagreb, Croatia \\ ${ }^{10}$ University of Zagreb School of Medicine, Zagreb, Croatia \\ ${ }^{11}$ Clinical Hospital Dubrava, Zagreb, Croatia \\ ${ }^{12}$ Catholic University of Croatia, Zagreb, Croatia \\ ${ }^{13}$ Children's Hospital Srebrnjak, Zagreb, Croatia
}

"These authors contributed equally to this work

received: 6.9.2020;

revised: 9.10.2020;

accepted: 16.10 .2020

\section{INTRODUCTION}

Major depressive disorder (MDD) is a complex disorder that can affect patients' ability to sleep, work, eat, and do daily practice. It affects approximately 1 in 5 adults at least once in a lifetime (Weihs \& Wert 2011). Up to a third of MDD patients have treatment-resistant depression (TRD) (Al-Harbi 2012). TRD is associated with increased suicide risk, sexual dysfunction, greater depression severity and body mass index $\geq 30 \mathrm{~kg} / \mathrm{m}^{2}$ (Saragoussi et al. 2017). Since genetic variants explain up to $42 \%$ of interindividual differences in antidepressant response, more precise and personalized way of MDD and TRD treatment such as pharmacogenomics (PGx) is necessary to improve outcomes and safety, and to reduce the economic burden of 136 billion USD annually in the United States alone associated with adverse drug reactions (Han et al. 2018, Johnson \& Bootman 1995).

\section{CASE PRESENTATION}

We present a case of a 50-year-old female patient with a history of arterial hypertension, MDD, insomnia, and ineffective antidepressant (AD) therapy for 21 years. Also, her mother was treated for MDD. In 1998, the patient was diagnosed with MDD and since then has been on numerous ADs with no clinical improvement. She started in 1998 with venlafaxine $37.5 \mathrm{mg}$ and in 2003 changed to paroxetine $20 \mathrm{mg}$ and maprotiline $25 \mathrm{mg}$, but she was still depressed, tired, and afraid. Later, she tried using another selective serotonin reuptake inhibitor sertraline, but it caused nausea. Computerized tomography brain scan and thyroid hormone analysis showed no pathological changes. In 2017 citalopram was introduced as new therapy, but with no improvements and some side effects. In 2018, she started using duloxetine $30 \mathrm{mg}$. Additionally, she used amitriptyline and fluvoxamine, which didn't have positive effect, and ramipril. In 2019, she was referred to St. Catherine Specialty Hospital with severe depression symptoms and thoughts of hurting others. She had reminiscent thoughts of childhood family trauma (father unintentionally cutting her arm with a knife), which she associates as the present condition's cause. Since her past medications were ineffective, we did PGx with RightMed $^{\circledR}$ panel which determines single nucleotide polymorphisms using TaqMan real-time PCR to see if there were significant drug-drug or drug-gene interactions (DGIs). The panel analyze 111 polymorphisms in 25 genes responsible for the synthesis of drug metabolizing enzymes, drug transporters, drug receptors and other proteins important for drug function, as well as for prothrombic factors (II, V and methyltetrahydrofolate reductase (MTHFR)) (Rogulj et al. 2019). She started taking PGx-guided medications including bupropion $150 \mathrm{mg}$ and trazodone $75 \mathrm{mg}$. However, because of rash, a common adverse effect, therapy was changed according to PGx to vortioxetine $10 \mathrm{mg}$ (moderate DGI), quetiapine $25 \mathrm{mg}$ (minimal DGI) and lorazepam (as needed) in collaboration with Psychiatry Hospital „Sveti Ivan "Zagreb. We also introduced support 10-day deep Transcranial Magnetic Stimulation (dTMS) session. After 5-6 weeks, she felt better, slept better and had more 
Table 1. Drugs the patient has used and their respective genes, genotype, phenotype and metabolic status

\begin{tabular}{|c|c|c|c|c|}
\hline Gene & Genotype & Phenotype & Metabolic status & Drugs included in patient's therapy \\
\hline CYP3A4 & $* 4 / * 35$ & Normal & Normal activity & quetiapine, trazodone \\
\hline CYP3A5 & $* 1 / * 3$ & Intermediate & Decreased activity & quetiapine, trazodone \\
\hline CYP2C19 & $* 2 / * 2$ & Poor & No to very low activity & $\begin{array}{l}\text { amitriptyline, sertraline, } \\
\text { citalopram, venlafaxine }\end{array}$ \\
\hline CYP2B6 & $* 1 / * 1$ & Normal & Normal activity & bupropion \\
\hline CYP2D6 & $* 4 / * 35$ & Intermediate & Decreased activity & $\begin{array}{l}\text { fluvoxamine, paroxetine, } \\
\text { vortioxetine, venlafaxine }\end{array}$ \\
\hline HRT2A & rs7997012 GG & $\begin{array}{c}\text { Intron } \\
2 \text { genotype GG }\end{array}$ & $\begin{array}{c}16-18 \% \text { increased risk } \\
\text { of non-response to citalopram }\end{array}$ & citalopram \\
\hline GRIK4 & rs1954787 TT & $\begin{array}{l}\text { Risk of reduced } \\
\text { response }\end{array}$ & $\begin{array}{l}11 \% \text { increase in the risk } \\
\text { of not responding to citalopram }\end{array}$ & citalopram \\
\hline
\end{tabular}

energy for the first time in 21 years. Furthermore, another 6-7 weeks and five months later, the improvement in mood, cognitive functioning, and sleep continued, strengthened by improvements in Beck Depression Inventory (BDI), Hamilton Depression Rating Scale (HDRS), and Pittsburgh Sleep Quality Index (PSQI). HCL-32 Questionnaire had a score of $2 / 32$ prior to and after new therapy, while there was a negative screen on the Mood Disorder Questionnaire (MDQ) questionnaire.

\section{DISCUSSION}

For the last 21 years, the patient has been taking 10 ADs from various groups, but with no clinical improvement. Since she came to St. Catherine Specialty Hospital in 2019, we do not know why the patient has not used lithium or undergone electroconvulsive therapy before that timepoint. Regardless, PGx-tailored therapy was the logical next step (Primorac et al. 2020). The patient's result revealed homozygous CYP2C19 genotype $* 2 / * 2$, associated with poor metabolizer phenotype with no to very low enzyme activity, essential for metabolizing ADs like amitriptyline, sertraline and citalopram, which showed major DGIs (Table 1). Furthermore, venlafaxine showed moderate DGIs. Due to polymorphisms in HRT2A and GRIK4 receptors, there is significantly reduced likelihood of response to citalopram therapy (Kawaguchi \& Glatt 2014, McMahon 2016). CYP2D6 genotype *4/*35, an important enzyme for metabolizing ADs like fluvoxamine and paroxetine, showed decreased activity, and together with no to very low CYP2C19 activity could explain the experienced adverse effects of amitriptyline, sertraline and citalopram due to potentially high doses administered concerning to this metabolizer.

No interactions other than between AD drugs in her therapy were noted. Following PGx results, we suggested taking bupropion and trazodone, only available ADs with minimal DGIs. Soon she had a skin rash, probably due to bupropion being a strong inhibitor of CYP2D6. This enzyme can affect trazodone metabolism, increasing the body's exposure to it. Therapy changed to vortioxetine and quetiapine based on PGx. The introduction of an atypical antipsychotic was justified due to a hint of psychosis and the patient's thoughts of harming others. Two weeks after dTMS session, she felt better, and 5-6 weeks later she could sleep better and also further improved. Since ADs and antipsychotics usually take 5-6 weeks to fully show their clinical potential, we attribute overall improvement to PGx-guided therapy and acute improvement after 2 weeks to dTMS. Also, dTMS is most effective after longer periods, not a 10-day session (Rapinesi et al. 2015). After another 6-7 weeks and five months, she continued improving. Cognitive function and desire were regained, fatigue decreased, and she willingly returned to work. BDI, HDRS showed improvements in depression severity (BDI 25 vs. 8, HDRS 26 vs. 5). PSQI indicated overall better sleep. MDQ showed negative screen for bipolar disorder, while HCL-32 Questionnaire had a 2/32 score indicating no significant signs of bipolar disorder.

\section{CONCLUSION}

The patient has been taking 10 ADs for 21 years with no clinical effect. PGx testing showed major and moderate DGIs, as well as receptor polymorphisms which are significant in $\mathrm{AD}$ metabolism and could explain poor clinical outcomes. PGx-guided therapy brought us to our goals sooner, and the patient felt better, slept better, regained cognitive function and willingness to work. The results show that a personalized PGx approach in patients with TRD has great therapeutic potential.

\section{Ethical disclosure:}

The authors state that they have obtained appropriate institutional review board approval or have followed the principles outlined in the Declaration of Helsinki in 1995 (as revised in Edinburgh 2000) for all human or animal experimental investigations. In addition, for investigations involving human subjects, informed consent has been obtained from the participant involved. 


\section{Financial disclosure:}

The authors have no relevant affiliations or financial involvement with any organization or entity with a financial interest in or financial conflict with the subject matter or materials discussed in the manuscript. This includes employment, consultancies, honoraria, stock ownership or options, expert testimony, grants or patents received or pending, or royalties.

No writing assistance was utilized in the production of this manuscript.

\section{Acknowledgements: None.}

\section{Conflict of interest: None to declare.}

\section{Contribution of individual authors:}

Dragan Primorac - Conceived and designed the study and the analysis, wrote the paper.

Alen Juginović - Collected the data and wrote the paper.

Igor Filiplić, Ivan Mikula, Ines Lazibat \& Morana Brkljačić - Performed the analysis and collected the dana.

Damir Erceg - Performed the analysis, collected the data and wrote the paper.

\section{References}

1. Al-Harbi KS: Treatment-resistant depression: therapeutic trends, challenges, and future directions. Patient Prefer Adherence 2012; 6:369

2. Han C, Wang SM, Bahk WM, Lee SJ, Patkar AA, Masand PS et al: A Pharmacogenomic-based Antidepressant Treatment for Patients with Major Depressive
Disorder: Results from an 8-week, Randomized, Singleblinded Clinical Trial. Clin Psychopharmacol Neurosci 2018;16:469-480

3. Johnson JA, Bootman JL: Drug-related morbidity and mortality. A cost-of-illness model. Arch Intern Med 1995; 155:1949-1956

4. Kawaguchi DM, Glatt SJ: GRIK4 polymorphism and its association with antidepressant response in depressed patients: a meta-analysis. Pharmacogenomics 2014; 15:1451-1459

5. McMahon FJ, Buervenich S, Charney D: Variation in the Gene Encoding the Serotonin $2 A$ Receptor Is Associated with Outcome of Antidepressant Treatment. Am J Hum Genet 2006; 78:804-814

6. Primorac D, Bach-Rojecky L, Vađunec D, Juginović A, Žunić K, Matišić $V$ et al: Pharmacogenomics at the center of precision medicine: challenges and perspective in an era of Big Data. Pharmacogenomics 2020; 21:141-156

7. Rapinesi C, Bersani FS, Kotzalidis GD, Imperatori C, Del Casale A, DiPietro $S$ et al.: Maintenance Deep Transcranial Magnetic Stimulation Sessions are Associated with Reduced Depressive Relapses in Patients with Unipolar or Bipolar Depression. Front Neurol 2015; 6:16

8. Rogulj IM, Matišić V, Arsov B, Boban L, Juginović A, Molnar $V$ et al.: Dasatinib-induced nephrotic syndrome: a case of phenoconversion. Croat Med J 2019; 60:250 254

9. Saragoussi D, Touya M, Haro JM, Jönsson B, Knapp M, Botrel $B$ et al.: Factors associated with failure to achieve remission and with relapse after remission in patients with major depressive disorder in the PERFORM study. Neuropsychiatr Dis Treat 2017; 13:2151-65

10. Weihs $K \&$ Wert JM: A primary care focus on the treatment of patients with major depressive disorder. Am J Med Sci 2011; 342:324-330

Correspondence:

Prof. Dragan Primorac, $M D, P h D$

St. Catherine Specialty Hospital

Trpinjska 7, 10000 Zagreb, Croatia

E-mail: office@draganprimorac.com 